\title{
Aortic valve incompetence and replacement in rheumatoid arthritis
}

\author{
J. M. I. IVESON, U. THADANI, M. IONESCU, AND V. WRIGHT \\ From the Department of Rheumatology, Cardiology, and Cardiothoracic Surgery, \\ The General Infirmary at Leeds
}

\begin{abstract}
Iveson, J. M. I., Thadani, U., Ionescu, M., and Wright, V. (1975.) Annals of the Rheumatic Diseases, 34, 312-320. Aortic valve incompetence and replacement in rheumatoid arthritis. Five cases of aortic incompetence and nodular seropositive rheumatoid arthritis are presented. Four cases underwent aortic valve replacement. Two of these had granulomatous involvement of the aortic cusps similar to subcutaneous rheumatoid nodules, and another showed a nonspecific fibrosis. One case had definite coincidental rheumatic aortic and mitral heart disease. Two patients had undergone pericardectomy previously for constrictive pericarditis. Good results were obtained in all four operated cases and cardiac surgery enabled continuation of rehabilitation for the rheumatoid arthritis, including major orthopaedic procedures.

A review of 22 cases from the literature with rheumatoid granulomata within the aortic valve shows that they are associated with mitral valve granulomata in $63.6 \%$. Congestive cardiac failure was found in $75 \%$. Macroscopical evidence of aortic incompetence was seen in $36.8 \%$ and of aortic stenosis in $15.8 \%$. Associated pericarditis occurred in $59.1 \%$, which was severe or complicated in $13.6 \%$. The associated arthritis was severe in $77.8 \%$ with subcutaneous nodules $(71.5 \%)$, rheumatoid factor $(83.6 \%)$, and episcleritis $(66.6 \%)$. From these cases and a review of the literature the following points are emphasized. (1) Both the granulomatous and nonspecific aortic valvulitis of rheumatoid arthritis may result in significant haemodynamic abnormality. (2) The valve lesions found are often clinically and macroscopically indistinguishable from rheumatic valve lesions. (3) Granulomata, when present, are usually found in the valve cusp or ring and only occasionally in the aortic wall. (4) Associated joint disease, although usually severe, may be mild. (5) The valve lesion may be accompanied by a severe pericardial involvement-either tamponade or constriction. (6) Aortic valve replacement for aortic incompetence in rheumatoid arthritis is both feasible and worthwhile, despite severe joint disease.
\end{abstract}

The concept of rheumatoid heart disease has received only gradual acceptance, but statistical analysis strongly indicates its existence (Khan and Spodick, 1972). Clinically there are no diagnostic criteria and the pathological changes are often nonspecific, but occasionally, as in the original descriptions by Baggenstoss and Rosenberg (1941, 1944), a specific diagnosis is possible because of the presence of rheumatoid granulomata, microscopically indistinguishable from subcutaneous nodules, within the heart itself. These may lie in the pericardium, myocardium, endocardium, or the valves themselves.

Rheumatoid nodules within the aortic valve were described in the original post-mortem reports of 0 rheumatoid granulomata in cardiac structures (Baggenstoss and Rosenberg, 1941, 1944), and since then there have been occasional reports of this involvement, in some of which signs of aortic in- $\sigma$ competence were present. The valve lesion has often $N$ been mild and haemodynamically insignificant $N$ (Weintraub and Zvaifler, 1963; Bulkley and Roberts, 1973) and the impression is given that rheumatoid heart disease is a rare cause of severe aortic incom- $\stackrel{\infty}{\infty}$ petence. There is only one detailed report in the literature of aortic valve replacement for rheumatoid : granulomatous disease (Barker, 1971), although 


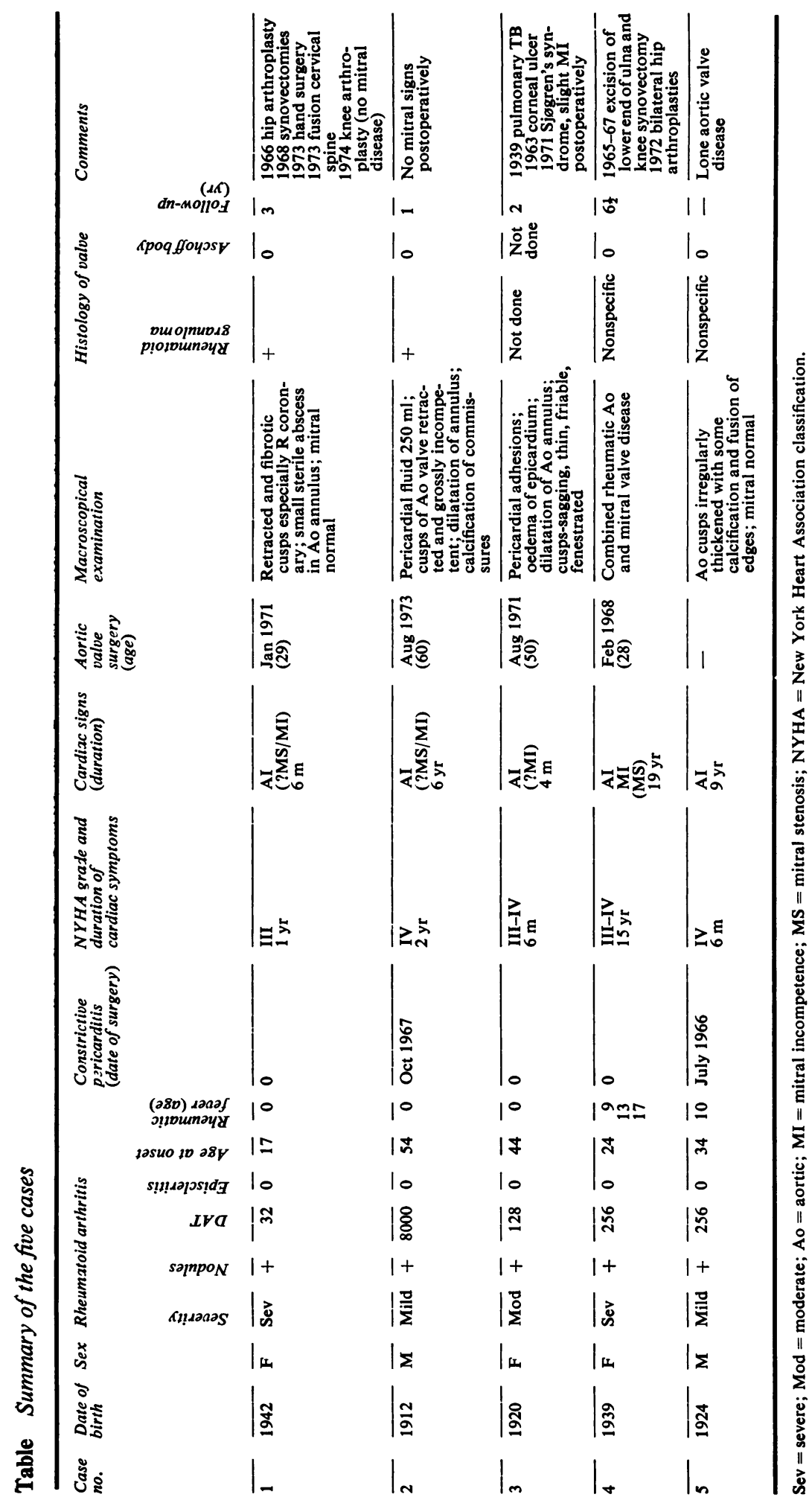


Cosh (1972) mentions the use of cardiac surgery in rheumatoid valvular disease, and it has been considered in individual cases (Legier, 1966).

\section{Materials and methods}

The Cardiothoracic Unit at the General Infirmary at Leeds replaces approximately 30 aortic valves annually. During the 5-year period, 1968-1973, no cases of ankylosing spondylitis with aortic incompetence were referred for valve surgery, but five cases of rheumatoid arthritis with aortic incompetence of such severity as to require valve replacement have been seen. Four of these five underwent successful valve surgery for progressive left ventricular failure with good results. One of these four had surgery elsewhere and one patient died before surgery could be performed. Some of the clinical and pathological features of these five are presented.

\section{CLINICAL MATERIAL (TABLE)}

\section{General}

Three were female and two male, with ages ranging from 28 to 60 years at the time of aortic valve replacement. The two youngest were both female aged 28 and 29 . Of these two, one (Case 4) had definite rheumatic aortic and mitral valve disease but the other (Case 1) had histologically confirmed rheumatoid valvulitis. Except for the histology, they had several similarities, in particular the excellent results of cardiac surgery despite the severity of the joint disease, which necessitated multiple orthopaedic operations.

The arthritis had been present for 5-13 years (mean nine years) and was either moderately severe or severe in three cases and mild in two. All had seropositive nodular erosive arthritis fulfilling the A.R.A. criteria. Four had received long-term treatment with corticosteroids.

\section{Associated diseases}

Three patients gave no history of rheumatic fever, although Case 4 had had three attacks and Case 5 one attack but without known evidence of cardiac involvement. Case 3 had a previous history of pulmonary tuberculosis and developed Sjøgren's syndrome with the arthritis. Cases 2 and 5 had each had pericardectomies for rheuma- $\sigma$ toid constrictive pericarditis, one 5 years before valve $\overrightarrow{0}$ replacement and the other 3 years before death in congestive failure. In the latter case the diastolic thrill was $\vec{\omega}$ palpated at pericardectomy and in the former the diastolic murmur was first heard shortly after it.

No patient had clinical or laboratory evidence of syste- $\dot{\omega}$ mic lupus erythematosus, syphilitic or spondylitic aortitis, Marfan's syndrome, or subacute bacterial endocarditis.

\section{CLINICAL PICTURE}

The history and findings on examination of the cardio- $\frac{\text { ? }}{3}$ vascular system were characteristic of aortic valvular $\vec{P}$ insufficiency from any cause. All patients had experienced $\stackrel{D}{C}$ either angina or left ventricular failure with exertionale dyspnoea, paroxysmal nocturnal dyspnoea, and acute $\stackrel{\oplus}{\oplus}$ attacks of left ventricular failure, or both. It was the $\vec{\varphi}$ deterioration in left ventricular function which precipstated surgical intervention. Deterioration was rapid $\mathbf{1}$. Case 3, the onset and progression suggesting rupture of the aortic cusp. Three of the five had episodes of congestize failure also. In all, except one case, murmurs were heard

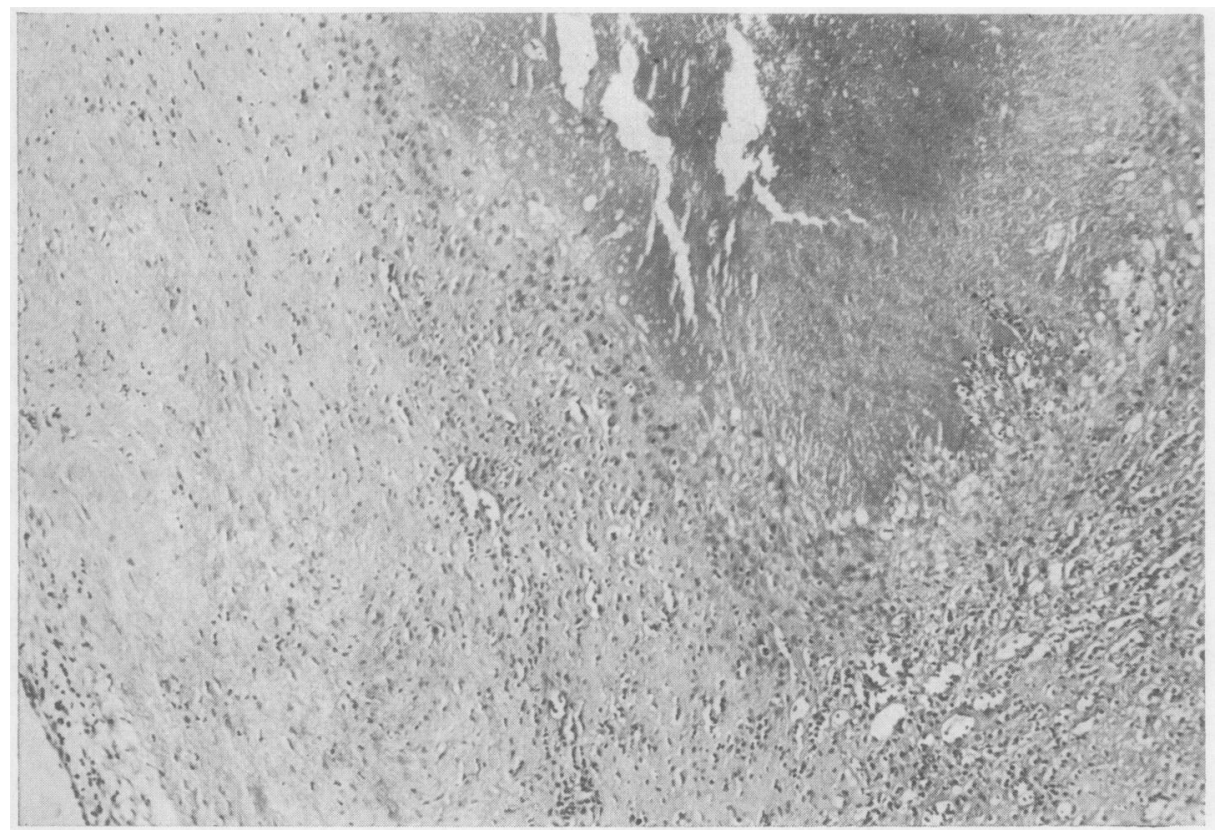

FIG. 1 Section of the nodule in the aortic cusp of Case 1, showing fibrinoid necrosis, pallisading and chronic inflammatory cell infiltration. $\times 36$ 
in the mitral area in addition to the characteristic long early diastolic murmur at the left sternal edge.

\section{SURGERY}

This was undertaken on four of the five cases. The fifth (Case 5) died from ventricular fibrillation while recovering from congestive cardiac failure. The interval between the onset of rheumatoid arthritis and aortic valve replacement was between 5 and 13 years, mean 8.5 years. Two valves were replaced with heterologous pericardial grafts and two with homologous fascia lata grafts.

\section{MACROSCOPICAL EXAMINATION}

The gross appearances of the aortic valves were similar to those expected in rheumatic valvulitis, with irregularly thickened and retracted cusps with occasional calcification of the commissures. No specific feature suggested the underlying rheumatoid granulomatous involvement in the two cases in which it was present. The annulus of the aortic valve was dilated in Cases 2 and 3 , and a small sterile abscess was found in the aortic annulus of Case 1. The cusps of Case 3 were thin, friable, fenestrated, and sagging. The tissues in general and the aortic tissue in particular were found to be fragile. An adhesive pericarditis with a markedly thickened $(15 \mathrm{~mm})$ oedematous epicardium was seen in Case $3.250 \mathrm{ml}$ pericardial fluid were present in Case 2, a previously pericardectomized case. The mitral valve was noted on palpation to be normal in Cases 1 and 5, but there is no record in Cases 2 and 3.

\section{HISTOLOGY}

Cases 1 and 2 had evidence of a rheumatoid granulomatous process within the valve leaflet. In Case 1 extensive areas of fibrinoid necrosis were fringed by histiocytes (a few of which were foamy) which were forming into illdefined pallisades (Fig. 1). The connective tissue showed patchy lymphoid infiltration around the vessels. In Case 2 the valve was thickened by fibrous tissue which in some areas had become amorphous or occasionally calcified (Fig. 2). These areas were surrounded by pallisaded histiocytes and chronic inflammatory cells. These changes were found in the valve cusps towards the aortic ring and not in the aorta itself (Fig. 3).

The aortic valve from Case 3 was not sent for histology and that of Case 4 was nonspecific, although consistent with chronic rheumatic valvulitis. The histology in Case 5 was again nonspecific with fibrosis, a small area of calcification, and a slight increase of vascularity with diffuse perivascular infiltration by lymphocytes. There were no rheumatoid granulomata, nor were Aschoff bodies seen in either of these two cases. In no case was there any histological evidence of the aortitis of ankylosing spondylitis, or of other causes of aortic valve incompetence.

\section{FOLLOW-UP}

The period of follow-up since operation has varied between 1 and $6 \frac{1}{2}$ years (mean 3.5 years). The results have been good both subjectively and objectively, with relief of cardiac symptomatology in all four cases. The cardiac signs have completely disappeared in two of these. The mitral pansystolic murmurs noted in all four operated cases preoperatively were heard in only one (Case 3) postoperatively. Preoperative mitral diastolic murmurs in Cases 1,2 , and 4 have not been heard postoperatively, although Case 2 has a mild aortic leak 1 year postoperatively. Cardiac drugs were withdrawn in three of the four

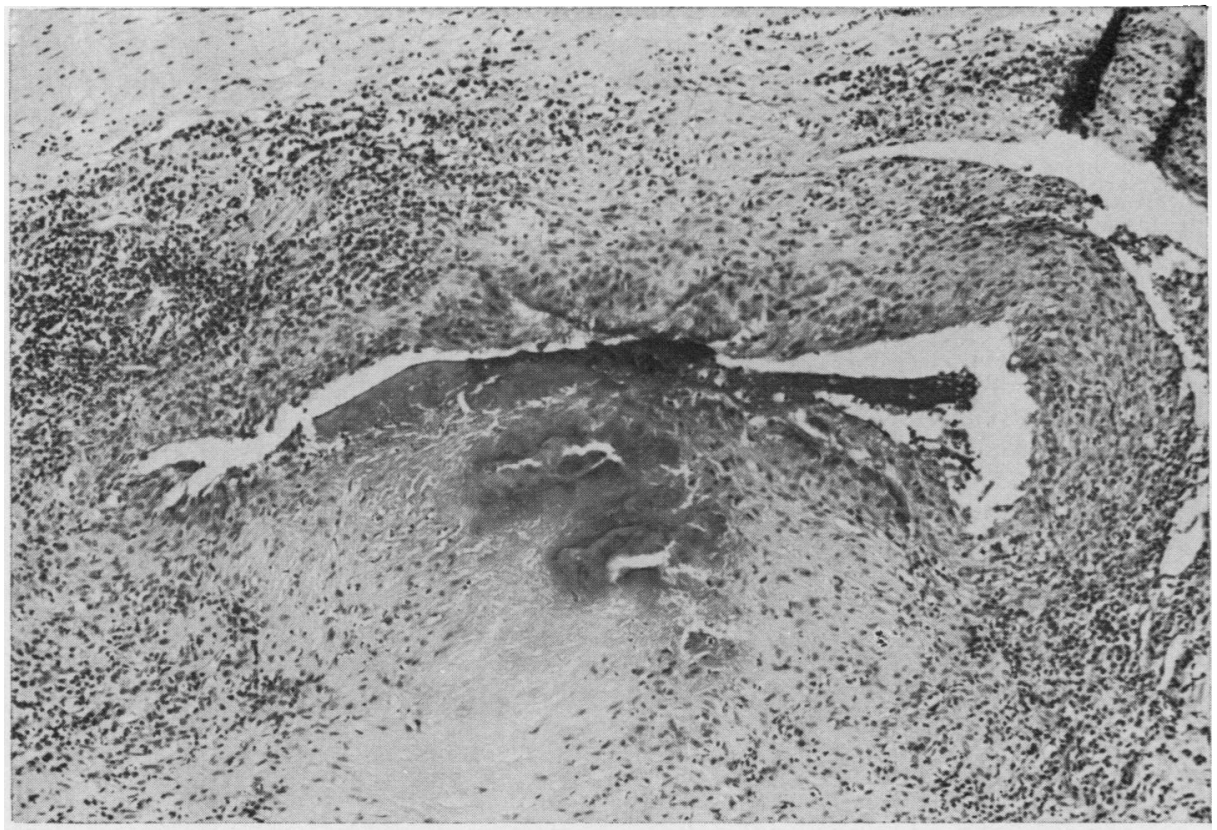

FIG. 2 Area of the aortic leaflet from Case 2, showing fibrinoid necrosis and pallisaded histiocytes. 


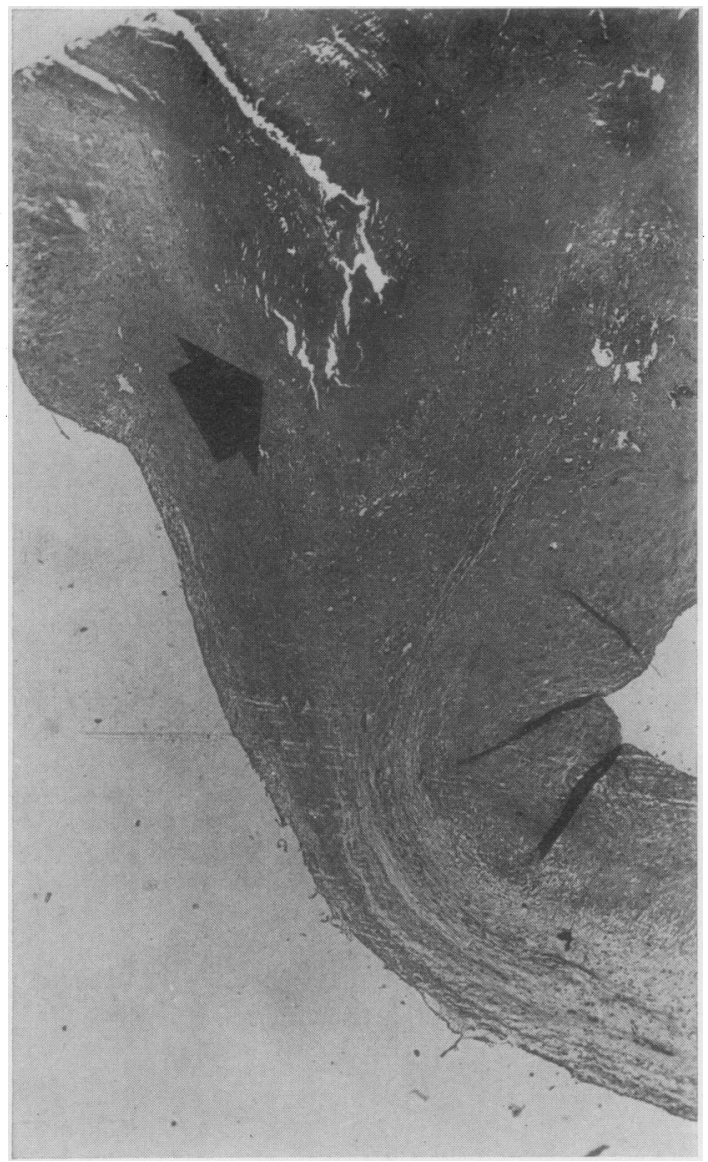

FIG. 3 Low-power view of the cusp from Case 1, showing the site of the nodule. $\times 3$

but have recently been reintroduced in two, one because of a tachycardia and the other because of the development of cardiomegaly. Clinical improvement has allowed the continuation of planned orthopaedic surgery. Case 1 has had two hand operations and fusion of the cervical spine for painful atlantoaxial subluxation, and Case 4 bilateral Charnley replacement arthroplasties to the hips. No unforeseen anaesthetic or surgical hazards were encountered and the postoperative course was not unduly complicated. The dosage and duration of treatment with corticosteroids have not been considered a contraindicacation to surgery and no evidence of hypoadrenalism was encountered.

\section{Discussion}

In 1941, Baggenstoss and Rosenberg reported finding nodules with a histological appearance similar to that of a subcutaneous rheumatoid nodule in the aorta, pericardium, and aortic and mitral valves of a patient with peripheral arthritis with ankylosis and mitral stenosis. A report followed in 1944 by the same authors of two cases of rheumatoid disease with granulomata in the aortic and mitral valves. They considered the valve lesion to be rheumatic in origin. Bywaters (1950), in classifying cardiac lesions found in association with rheumatoid arthritis, first gave $\overrightarrow{7}$ prominence to rheumatoid heart disease, as distinct $t^{\text {? }}$ from rheumatoid arthritis with coexistent rheumatice heart disease. He recorded a case of granulomatous $\overline{\bar{s}}$. aortic valve disease which had coexistent fibrinous $\overrightarrow{-}$ pericarditis, and noted reports in the literature of other cases with rheumatoid granulomata within thees heart, but not the aortic valve. Since then it has be- $\overrightarrow{0}$ come customary to recognize two forms: (1) agranulomatous one in which rheumatoid granulo- $\vec{\omega}$ mata may be seen in any cardiac structure; and (2) lesions with a nonspecific histology such as pericar-a ditis, but also including patchy valvular fibrosis, $\omega$ myocarditis, and endocarditis (Hollingsworth, 1968) Less than half of the lesions found at autopsy arew associated with clinical manifestations (Lebowitz, $\vec{N}$ 1966). This discrepancy is well illustrated by rheuma- 음 toid pericarditis, the prevalence of which is as highas $30-40 \%$ at autopsy (Sokoloff, 1953; Cathcart and Spodick, 1962; Lebowitz, 1963) but which is apparento clinically in only $10 \%$ of hospitalized patients, even $\stackrel{\text { ? }}{?}$ when searched for diligently (Kirk and Cosh, 1969). $\vec{\bullet}$

Often the heart disease is overshadowed by the v severe generalized rheumatoid process (Weintrat and Zvaifler, 1963) which so restricts the patien⿳亠口冋丁 activity that exertional symptoms do not arise (Hart, 1969; Barker, 1971). These factors, together with thee frequent mildness of cardiac lesions which are only occasionally haemodynamically significant (Wein- traub and Zvaifler, 1963) have suggested to some⿳亠丷厂 authors that the cardiac lesions of rheumatoid arthri 3 tis are an academic curiosity rather than a clinica problem (Downie and Buchanan, 1969). Bonfiglio. and Atwater (1969) felt that the cardiac lesions maye not be as benign as their reputation suggests, having found cardiac granulomata in 2 of 47 autopsied 3 . patients whom they reviewed, and this agrees with then 1-3\% figure quoted by Sokoloff (1953).

Barker (1971) was the first to report finding rheumatoid granulomata in the aortic valve removed? at cardiac surgery for gross aortic incompetence. She found at least 64 patients previously reported with cardiac granulomata.

In reviewing the literature since 1941, we have found 18 reports of 22 cases in which aortic cusps and valve ring have been involved by definite rheumatoid $\omega$ granulomata (Baggenstoss and Rosenberg, 1941, 1944; Bywaters, 1950; Bevans, Nadell, Demartini and Ragan, 1954; Ellman, Cudkowicz and Elwood 1954; Maher, 1954; Skogrand, 1956; Cruikshank; 1958; Goehrs, Baggenstoss and Slocumb, $1960 ; \overline{-}$ Lassiter and Tassy, 1965, Legier, 1966; Schwartz $\underset{\mathrm{P}}{\mathrm{P}}$ 1967; Carpenter, Golden, and Roberts, 1967? Roberts, Kehoe, Carpenter and Golden, $1968 ; 0$ Lef kowits, Kaplan and Young, 1968; Harris, 1970 
Barker, 1971; Howell, Say, and Hedworth-Whitty, 1972.) During this same period mitral valve granulomata were reported in 24 cases, the tricuspid was involved in eight and the pulmonary in five. This frequency of valvular involvement conforms to that found in a smaller group by Roberts and others (1968), who noted the similarity of this frequency to that in rheumatic disease.

The aortic valve may be involved alone, but more frequently the mitral and aortic valves are involved together (14 of 22 cases). Occasionally the mitral alone (Schoene and Risse, 1964) or all four valves have been involved (Bevans and others, 1954; Ellman and others, 1954; Carpenter and others, 1967; Roberts and others, 1968). The valvular lesions were frequently associated with both granulomatous involvement of other cardiac structures, such as the myocardium, endocardium, and pericardium, and nonspecific lesions. Some reports do not specify the site of the granulomata (Clark and Bauer, 1948; Graef, Hickey, and Altmann, 1949; Levin, Kaplan, Marcus, Weinberger, and Patterson, 1955; Bonfiglio and Atwater, 1969).

Gross examination of the involved valves has generally shown the nonspecific changes of stiffening, thickening, opacification, and shrinkage of the cusps with varying degrees of distortion. Although rheumatoid nodules may be visible macroscopically in the valve or annulus as in $5(22.7 \%)$ of the 22 cases, a careful microscopical search is usually necessary if the granulomatous process is not to be missed (Bevans and others, 1954; Lebowitz, 1963; Barker, 1971). It has been said (Lebowitz, 1963) that no valves grossly resembling healed rheumatic endocarditis in patients with rheumatoid arthritis should be labelled as such until after careful microscopical examination. The gross appearances of the aortic valves in the four nonrheumatic cases presented here confirm this opinion. Although the histology in two was nonspecific, it revealed a granulomatous valvulitis in two. Occasionally the valves may be macroscopically normal and microscopically involved, as in the two cases described by Bevans and others (1954).

The resultant valvular distortion was of such severity as to have produced interference with valvular function in eleven cases, the most frequent abnormality being aortic incompetence in $36.8 \%$. Aortic stenosis was found in three cases, mixed stenosis and incompetence in two, and normal valves found in two. Four valves were only thickened, and another was nodular but neither stenosed nor incompetent. Coexistent granulomatous mitral valve involvement was found in 14 of the 22 cases $(63.6 \%)$. In three mitral stenosis was present; in another mixed stenosis and incompetence, and in another mitral incompetence. Two mitral valves were nodular but otherwise functionally unimpaired, one only thickened and another normal. A description of macroscopical appearance was not available in five, although they were microscopically abnormal. In only one of the cases of aortic incompetence were the clinical signs absent, and in only three of 15 in which cardiac signs were recorded were no murmurs heard. In two of these this may have been related to associated pericardial effusion. Of the 16 cases in which a cause of death is given, tamponade may have contributed in two. Complete heart block was seen in two of the 22 cases and 2:1 heart block with Stokes-Adams attacks in another. In all three there was associated granulomatous involvement of the mitral valve, and in two of the conducting tissue also. The varying degrees of heart block that may be seen in rheumatoid heart disease are usually due to granulomata involving the endocardium and myocardium around the conducting tissue and are not secondary to an associated aortic abnormality as is usually found in ankylosing spondylitis. In none of our cases was there any evidence of a conduction defect.

In this discussion we have confined our attention to rheumatoid nodules that lie in the valve leaflet or ring, but they have also been seen in the aortic root (Sinclair and Cruikshank, 1956; Cruikshank, 1958; Schoene and Risse, 1964), where they are usually solitary but may be accompanied by involvement of the valve leaflet (Sinclair and Cruikshank, 1956). Granulomatous involvement of the wall of the ascending aorta and the aortic valve may occur together (Ellman and others, 1954; Roberts and others, 1968) and a granulomatous aortitis (Weintraub and Zvaifler, 1963) has been recorded. An association of rheumatoid arthritis with aortic aneurysm has been suggested (Weinberger and Sacks, 1967) and calcific aortic stenosis is said to be more frequent (Lebowitz, 1963).

Both in those cases in which aortic incompetence was diagnosed during life and when auscultatory signs have been absent or of doubtful significance, left ventricular or congestive failure has been present before or contributed to death. Of the 16 patients in whom granulomata were subsequently found in the aortic valve cusp or root, and who had adequately detailed case histories, $12(75 \%)$ had evidence of cardiac failure (or tamponade) before death. This suggests that any rheumatoid patient who develops cardiac failure should be scrutinized for a surgically correctable valve or pericardial lesion.

The arthritis of the rheumatoid disease with granulomatous aortic involvement was severe in $77.8 \%$, with subcutaneous nodules in $78.5 \%$, high levels of rheumatoid factor in $83.4 \%$, and episcleritis in $66.6 \%$. There are, however, some notable exceptions when the joint disease has been either minimal (Lef kowits and others, 1968) or even unsuspected during life (Legier, 1966). This presentation of the valvular involvement before the joint disease has developed to any degree has also been noted in ankylosing 
spondylitis (Bulkley and Roberts, 1973). One of our patients (Case 5) had only mild joint disease, although seropositive and nodular; and Barker's (1971) case, who also underwent cardiac surgery, had moderate disease.

The mean age of the 22 patients was 57.6 years (range 45-72) at the time of death and the sex distribution was male:female $1: 2$. Duration of joint disease has varied from 4 to 30 years with a mean of 13 years. In comparison, two of our cases were less than 30 at the time of operation and Case 5 was aged 44 at the time of his death in congestive failure. The mean disease duration in our five cases was 9 years.

Weintraub and Zvaifler (1963) drew attention to a clinical association between rheumatoid arthritis and aortic incompetence which they considered might be more common than had previously been thought, reporting five cases of this combination seen within an 18-month period in patients with severe, markedly seropositive nodular rheumatoid arthritis. In only one of these was valvular incompetence haemodynamically significant and of the two who came to autopsy, neither showed any granulomatous valvular change, although one had a granulomatous aortitis and the other a granuloma in the myocardium at the base of the aortic valve. The PR interval was increased in two of the five. Our experience agrees with theirs and suggests that it is probably not as uncommon as has generally been supposed. Our cases have differed, however, in having either granulomatous or fibrotic valvulitis, rather than aortitis, which was haemodynamically significant to the extent of requiring surgical correction-a procedure which gives excellent results. The valvular disorder has not only occurred in severe rheumatoid arthritis but has in two cases occurred with mild to moderate arthritis. It may be found in relatively young patients, and is not always a disease of the elderly. The hazards of delaying surgery in aortic incompetence from any cause are well known and are illustrated by Case 5, who probably had a rheumatoid valvulitis.

Although significant valvular dysfunction in rheumatoid arthritis will usually be the result of either coexistent rheumatic heart disease or a nonspecific rheumatoid lesion, the occasional case of granulomatous involvement will be missed if all valves removed surgically and at post mortem are not scrutinized microscopically. This may apply to the mitral as well as the aortic valve. Recent studies by echocardiography suggest that mitral valve dysfunction in rheumatoid arthritis is not uncommon (Bacon and Gibson, 1974) and, as shown above, granulomatous involvement of the mitral valve may be shown at post mortem.

Although granulomatous aortic involvement has not been shown in Cases 3 and 5, we feel that they are probably examples of rheumatoid aortic valve disease. Case 3 gave no history of rheumatic fever and had a

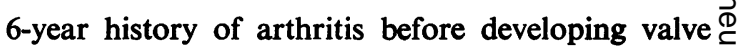
disease. The persistent mitral pansystolic murmur 3 could be explained on the basis of the frequent $\frac{}{\rho}$. concurrence of aortic and mitral valve disease in rheumatoid as in rheumatic heart disease. The histol- $\overrightarrow{\vec{F}}$ ogy in Case 5 was nonspecific. However, the association with constrictive pericarditis (a recognized complication of rheumatoid arthritis and one which was present together with a granulomatous aortic valve in Case 2) make it probable that this too was rheumatoid in origin, despite the previous history of ${ }^{\infty}$ rheumatic fever. The absence of mitral disease and $\vec{\nabla}$ the detection of the valve lesion two years after the $\vec{A}$ onset of rheumatoid disease tend to support this view.

The literature suggests that rheumatoid nodules are found more frequently within the valves than in other cardiac structures, and that the relative fre- $\stackrel{\omega}{\perp}$ quency of involvement of the valves themselves con- $\rightarrow$ forms to that described for rheumatic valve disease. $\frac{\omega}{N}$ That is thought to be related to the gradient across these valves and suggests that there is a predilection $\frac{}{5}$ for the formation of rheumatoid nodules in those structures most subject to stress. It is unknown if valvular involvement is a primary response or whether $\frac{C}{c}$ the granulomatous process affects a valve which is $\stackrel{\oplus}{+}$ already the site of abnormal stresses as a result of $\vec{\theta}$ previous disease, either rheumatic fever or a nof or specific rheumatoid lesion.

Pericardial lesions were found in 13 of the 22 case $(59.1 \%)$ from the literature and in three of the five cases presented here. This frequency is higher than recorded generally and probably reflects the severity of the rheumatoid disease in many of these cases. In nine the changes were mild, consisting of an adherent or fibrinous pericarditis with slight thickening. The pericardium of one contained rheumatoid nodules (Carpenter and others, 1967) and the pericarditis in another had resulted in a small effusion of $100 \mathrm{ml}$ (Maher, 1954). In three of the $22 \div$ $(13.6 \%)$ the abnormalities were severe. One of the 3 . cases of Bevans and others (1954) died with $350 \mathrm{ml} \delta$ bloody fluid under great pressure within the peri- $₹$ cardium, which demonstrated a fibrinosanguinous 응 exudate layered upon an old adhesive pericarditis. That of Ellman and others (1954) had a dense fibrous adherent pericardium with an abscess posteriorly, which on microscopy revealed a typical rheumatoid o lesion. Lassiter and Tassy's (1965) case had $1000 \mathrm{ml} N$ milky fluid within the pericardial cavity, which also contained tags of grey fibrinopurulent exudate. Both $\omega$ layers of the pericardium were thickened. More recently, Metzger (1970) reported a rheumatoid $\stackrel{\odot}{\odot}$ patient dying as a result of aortic incompetence and $\stackrel{\Phi}{\oplus}$ cardiac failure, who had previously had cardiac tamponade successfully treated. The aortic valve had 0 several perforations and an aneurysm of the sinus of $\mathbb{\mathbb { Q }}$ Valsalva. Histology was suggestive, but not conclu- $\frac{?}{\mathbb{Q}}$ sive, of a rheumatoid granuloma within the valve. 
It appears that pericardial abnormalities are not only common in cases of rheumatoid arthritis with granulomata within the aortic valve but are also often more severe and likely to result in cardiac tamponade or gross pericardial thickening suggestive of constriction. This predisposition would explain the concurrence in two of the cases described here of constrictive pericarditis and aortic valve disease - an association not previously recorded. One of these cases (Case 2) also had $250 \mathrm{ml}$ pericardial fluid present at the time of valve surgery, 6 years after pericardectomy. This association does not necessarily involve severe joint disease. The three cases from the literature described above had severe arthritis, but Case 2 had very mild joint involvement. Although this may only represent the chance association of two uncommon cardiac complications of rheumatoid arthritis it more probably represents a severe rheumatoid pancarditis. It does, however, support the view that both constrictive pericarditis and valvulitis of sufficient severity to produce haemodynamic dysfunction are occasional, but specific, complications of rheumatoid disease. It would be difficult to assess whether the combination of marked pericardial and valve lesions is any more disabling than either lesion alone, but it would be reasonable to expect an indistensible heart to tolerate an incompetent valve poorly.

The results of aortic valve replacement in our cases compare favourably with those recorded in ankylosing spondylitis (Malette, Eiseman, Danielson, Mazzo- leni, and Rams, 1969; Spangler, McCallister, and McGoon, 1970; Schilder, Harvey, and Hufnagel, 1956) and Reiter's disease (Paulus, Pearson, and Pitts, 1972; Cosh, Barritt, and Jayson, 1973). Of the 11 operated cases of ankylosing spondylitis reported, two had died. Bulkley and Roberts (1973) also record postmortem studies on a further eight cases of ankylosing spondylitis, five of whom had died within 12 months of valve replacement.

As a result of the experience gained with our five cases we feel that aortic valve surgery in rheumatoid arthritis, both for a granulomatous and nonspecific rheumatoid valvulitis, is worthy of consideration even when the joint disease is severe. This conclusion is supported by M. W. J. Boyd (personal communication, 1974). He has seen two patients with rheumatoid arthritis who have responded well to the insertion of mechanical valves over a period of 11 and 4 months, respectively. Yates and Scott (1975, see following article), however, urge caution in emphasizing that the prognosis depends very much on the general state of the patient.

We are grateful to Dr. W. Whitaker of the Department of Cardiology, General Infirmary, Leeds, Dr. W. C. Walker, Pinderfields General Hospital, and Dr. D. R. L. Newton, Middlesbrough General Infirmary, for providing details of cases in their care, and to Dr. S. Holt of the Department of Pathology, the General Infirmary at Leeds, for her help in the preparation of the photographs.

\section{References}

Bacon, P. A., AND Gibson, D. G. (1974) Ann. rheum. Dis., 33, 20 (Cardiac involvement in rheumatoid arthritis)

BAGgenstoss, A. H., AND Rosenderg, E. F. (1941) Arch. intern. Med., 67, 241 (Cardiac lesions associated with chronic infectious arthritis)

_- (1944) Arch. Path. 37, 54 (Unusual cardiac lesions associated with chronic multiple rheumatoid arthritis)

BARKER, A. (1971) N.Z. med.J., 73, 14 (Rheumatoid arthritis and rheumatoid heart disease)

Bevans, M., Nadell, J., Demartini, F., and Ragan, C. (1954) Amer. J. med., 16, 197 (The systemic lesions of malignant rheumatoid arthritis)

Bonfiglio, T., AND Atwater, E. C. (1969) Arch. intern. Med., 124, 714 (Heart disease in patients with seropositive rheumatoid arthritis)

BulkLey, B. H., AND RoBerTs, W. C. (1973) Circulation 48, 1014 (Ankylosing spondylitis and aortic regurgitation)

Bywaters, E. G. L. (1950) Brit. Heart J., 12, 101 (The relation between heart and joint disease including 'rheumatoid heart disease' and chronic post-rheumatic arthritis (type-Jaccoud))

Carpenter, D. F., Golden, A., AND RoberTs, W. C. (1967) Amer. J. Med., 43, 922 (Quadrivalvular rheumatoid heart disease associated with left bundle branch block)

CathCART, E. S., AND Spodick, D. H. (1962) New Engl.J. Med., 266, 959 (Rheumatoid heart disease-a study of the incidence and nature of cardiac lesions in rheumatoid arthritis)

Clark, W. S., and Bauer, W (1948) Ann. rheum. Dis., 7, 39 (Cardiac changes in rheumatoid arthritis)

CosH, J. A. (1972) Rheumatol. and Phys. med., 11, 267 (The heart and the rheumatic diseases)

- BARritt, D. W., AND JAYson, M. I. V. (1973) Brit. Heart J., 35, 553 (Cardiac lesions of Reiter's syndrome and ankylosing spondylitis)

Cruikshank, B. (1958) J. Path. Bact., 76, 223 (Heart lesions in rheumatoid disease)

Downie, W. W., AND BuchanAN, W. W. (1969) Brit. J. hosp. Med., 2, 1933 (Rheumatoid arthritis-articular and systemic manifestations)

Ellman, P., Cudkowicz, L., AND Elwood, J. S. (1954) J. clin. Path., 7, 239 (Widespread serous membrane involvement by rheumatoid nodules) 
Goehrs, H. R., Baggenstoss, A. H., AND Slocumb, C. H. (1960) Arthr. and Rheum., 3, 298 (Cardiac lesions in rheumatoid arthritis)

Graef, I., Hickey, D. J., AND Altmann, V. (1949) Amer. Heart J., 37, 635 (Cardiac lesions in rheumatoid arthritis)

HARRIS, M. (1970) J. clin. Path., 23, 623 (Rheumatoid heart disease with complete heart block)

HART, F. D. (1969) Brit. med., J. 3, 131 (Rheumatoid arthritis: extra-articular manifestations)

HollingsworTH, J. W. H. (1968) 'Local and Systemic Complications of Rheumatoid Arthritis'. Saunders, Philadelphia

Howell, A., SAy, J., AND Hedworth-Whitty, R. (1972) Brit. Heart J., 34, 537 (Rupture of the sinus of Valsalva due to severe rheumatoid heart disease)

Khan, A. H., AND Spodick, D. H. (1972) Semin. Arthr. Rheum., 1, 327 (Rheumatoid heart disease)

KIRK, J., AND CosH, J. (1969) Quart. J. med., 38, 397 (The pericarditis of rheumatoid arthritis)

LASSITER, G. S., AND TASSY, F. T. (1965) Arch. intern. Med., 116, 930 (Malignant rheumatoid disease with aortic stenosis)

LeBowITz, W. B. (1963) Ann. intern. Med., 58, 102 (The heart in rheumatoid arthritis (rheumatoid disease)-a clinical and pathological study of 62 cases)

- (1966) Geriatrics, 21, 194 (The heart in rheumatoid disease)

LefKowITs, A., KAPLAN, S. B., AND Young, J. M. (1968) Arthr. and Rheum., 11, 494 (Rheumatoid granulomata of aortic valve ring causing fatal aortic insufficiency in a patient with minimal arthritis)

LEGIER, J. F. (1966) Arch. intern. Med. 117, 480 ((?Anarthritic) rheumatoid pancarditis with terminal acute hemorrhagic gastroenteropathy)

Levin, M. H., Kaplan, L., Marcus, S., Weinberger, H. J., and Patterson, J. (1955) Ann. rheum. Dis., 14, 430 (Heart in rheumatoid arthritis-a clinical-pathologic correlation of 43 autopsied patients)

MAHER, J. A. (1954) Arch. Path., 58, 354 (Dural nodules in rheumatoid arthritis)

Malette, W. G., Eiseman, B., Danielson, G. K., Mazzoleni, A., AND Rams J. J. (1969) J. thorac. cardiovasc. Surg., 57, 471 (Rheumatoid spondylitis and aortic insufficiency; an operable combination)

Metzger, A. L. (1970) Arthr. and Rheum., 13, 430 (In discussion of RomANoff, H., Rozin, R., AND Zlotnick, A. Cardiac tamponade in rheumatoid arthritis-a case report and review of the literature)

Paulus, H. E., Pearson, C. M., and Pitts, W. (1972) Amer. J. Med., 53, 464 (Aortic insufficiency in five patients with Reiter's syndrome-a detailed clinical and pathologic study)

Roberts, W. C., Kehoe, J. A., CARPENTER, D. F. AND Golden, A. (1968) Arch. intern. Med., 122, 141 (Cardiac valvular lesions in rheumatoid arthritis)

Schilder, D. P., Harvey, W. P., ANd Hufnagel, C. A. (1956) New Engl. J. med., 255, 11 (Rheumatoid spondylitis and aortic insufficiency)

Schoene, R. H., AND Risse, G. B. (1964) Ohio St. med. J., 60, 377 (Rheumatoid heart disease)

SCHWARTz, S. (1967) J. Amer. med. Ass., 201, 556 (Rheumatoid carditis)

Sinclair, R. J. G., AND Cruickshank, B. (1956) Quart. J. Med. 25, 313 (A clinical and pathological study of sixteen cases of rheumatoid arthritis with extensive visceral involvement)

Skogrand, A. (1956) Acta rheum. scand., 2, 17 (Visceral lesions in rheumatoid arthritis)

SoKolofF, L. (1953) Amer. Heart J., 45, 635 (The heart in rheumatoid arthritis)

SPANGler, R. D., McCallister, B. D., AND MCGoon, D. C. (1970) Amer.J. Cardiol., 26, 130 (Aortic valve replacement in patients with severe aortic valve incompetence associated with rheumatoid spondylitis)

WeINBERGER, H. J., AND SACKS, H. (1967) Arthr. and Rheum. 10, 321 (Aortic aneurysm and rheumatoid arthritis)

Weintraub, A. M., AND ZvaifLer, N. J. (1963) Amer. J. Med., 35, 145 (The occurrence of valvular and myocardial disease in patients with chronic joint deformity)

YATES, D. B., AND SCOTT, J. T. (1975) Ann. rheum. Dis., 34, 321 (Cardiac valvular disease in chronic inflammatory disorders of connective tissue: factors influencing survival after surgery) 